Diabetologia 10, 589-593 (1974)

(C) by Springer-Verlag 1974

\title{
Aortic Glucose Metabolism in the Diabetic Chinese Hamster*
}

\author{
Aram V. Chobanian, George C. Gerritsen, Peter I. Brecher, and Louis McCombs \\ Cardiovascular Institute, Boston University Medical Center, Boston, Massachusetts, and Diabetes and Atherosclerosis \\ Research, The Upjohn Company, Kalamazoo, Michigan, USA
}

\begin{abstract}
Summary. The influence of diabetes and insulin therapy on arterial glucose metabolism was studied in the Chinese hamster. Total glucose utilization and conversion of glucose to lactic acid, $\mathrm{CO}_{2}$, lipid, glycogen, and protein were significantly reduced in intima-media segments of diabetic hamster aorta incubated in vitro. The degree of reduction was greater in the ketotic than the non-ketotic diabetics. The abnormalities in glucose metabolism did not appear to be related to a defect in glucose transport. Administration of insulin in vivo for up to $72 \mathrm{~h}$ in doses
\end{abstract}

sufficient to normalize plasma glucose and insulin did not influence aortic glucose utilization. However, treatment with large doses of insulin, which produced marked hyperinsulinemia and mild hypoglycemia, corrected the observed reductions in glucose incorporation. Addition of insulin in vitro had no significant effect on aortic glucose metabolism.

Key words: Arterial metabolism, diabetes mellitus, arterial metabolism, insulin, Chinese hamster.
Despite the marked predisposition of diabetic patients to develop atherosclerotic disease, relatively little information is available concerning the metabolism of vascular tissue in diabetes. Previous studies have been limited primarily to animals with chemically induced diabetes where a number of abnormalities of arterial glucose metabolism have been noted. Arterial glucose uptake, oxidation, and incorporation into lactate, lipid and glycogen were depressed significantly in alloxan treated rabbits [1]. The abnormalities could be minimized by pretreatment of the animals with insulin, although insulin added in vitro had little influence on glucose utilization. The arterial incorporation of acetate into fatty acids appeared to be reduced in alloxan diabetic rats [2]. Insulin treatment has been reported to stimulate aortic lipid synthesis in streptozotocin treated rats [3] as well as in normal rats [4] and chickens [3]. However, in normal rat aorta, the increased lipid synthesis produced by insulin appeared to be confined to the arterial adventitia [5], suggesting that an effect on adipose cells was being measured. Chronic insulin treatment of normal chickens was observed to produce marked increase in intimal lipids [3]. It is uncertain whether these changes were secondary to a direct effect on intimal lipid synthesis or to the hyperlipidemia developed in response to insulin.

The current investigation has examined the influence of diabetes and of insulin therapy on arterial glucose metabolism in the Chinese hamster (cricetulus griseus). This animal model has many of the characteristics of the human disease and appears to be particularly suited for studying the influence of diabetes on the development of vascular disease. The diabetic animals may have varying degrees of severity of hyperglycemia and glycosuria, and plasma insulin

* Supported by USPHS Grant 12869 and the U.A. Whitaker Fund. may be reduced $[6,7]$. The inheritance of the diabetes appears to be controlled by several recessive genes [8]. The animals develop cataracts, retinal vascular changes, and basement membrane thickening of pancreatic capillaries $[9,10]$. We have observed that some of the diabetic hamsters also exhibit hyperlipidemia, increased arterial cholesterol content, and microscopic abnormalities of the arterial intima $[11$, $12]$.

\section{Materials and Methods}

The hamsters were obtained from the Upjohn colony. The diabetic animals were selected on the basis of glycosuria and hyperglycemia determined repeatedly during life. All diabetic animals were matched with a nondiabetic control of the same sex and of similar age and weight. All animals were maintained on Purina Mouse Breeder Chow.

The animals were fasted overnight prior to sacrifice. They were then bled from the orbital sinus and killed by decapitation. The total aorta was removed and the adventitia was carefully teased away. The remaining tissue, which was utilized for the metabolic studies, was found on microscopic examination to be comprised of the total intima and approximately three-fourths of the media. The tissues were opened longitudinally and incubated for $1-2 \mathrm{~h}$ at $37^{\circ} \mathrm{C}$ in $2 \mathrm{ml}$ KRB buffer ( $\mathrm{pH} 7.4$, gas phase $95 \% \mathrm{O}_{2}-5 \%$ $\mathrm{CO}_{2}$, glucose concentration $1-10 \mathrm{mM}$ ). Three aortas were pooled for use in each metabolic study. Uniformly labelled glucose ${ }^{14} \mathrm{C}$ obtained from the New England Nuclear Corp. was utilized as labelled substrate. The incubations were terminated with $0.2 \mathrm{ml}$ of $4 \mathrm{~N} \mathrm{H}_{2} \mathrm{SO}_{4}$. The tubes were shaken for an additional $45 \mathrm{~min}$ and the liberated $\mathrm{CO}_{2}$ was collected in plastic wells containing hydroxide of hyamine. Glucose, lactate, and pyruvate contents of the incubation solutions were determined by enzymatic techniques $[13,14]$. The 
medium glucose and lactate were also isolated by TLC at $4^{\circ} \mathrm{C}$ utilizing a solvent system of ethanol: water: ammonium hydroxide $(80: 16: 4)$ and the radioactivity of these TLC fractions was determined as described [15].

Following incubation, the tissues were washed $5 \mathrm{x}$ with $10 \mathrm{ml}$ saline, blotted, and minced. The tissues were then homogenized in chloroform: methanol $(2: 1)$, and the arterial lipids were extracted according to the procedure of Folch et al. [16]. The major lipid classes were separated by TLC, and the radioactivity of the fractions was determined. Tissue proteins were precipitated with $0.4 \mathrm{~N}$ cold trichloroacetic acid (TCA), and the radioactivity of the protein fractions was measured as previously described [17]. DNA content was assayed by the method of Ceriotti [18]. For the analysis of glycogen radioactivity, carrier glycogen was added to the TCA supernatant and the glycogen was precipitated with $95 \%$ ethanol. The precipitate was washed $2 x$ with $5 \mathrm{ml}$ of $70 \%$ ethanol and the glycogen hydrolyzed with $2 \mathrm{ml}$ of $1.0 \mathrm{~N}$ sulfuric acid [19]. The glucose radioactivity derived from the glycogen fraction was determined as described above.

In selected experiments, the diabetic hamsters were treated prior to sacrifice with crystalline insulin in daily doses ranging from $0.6 \mathrm{U} / \mathrm{kg}$ to $30 \mathrm{U} / \mathrm{kg}$ for periods of up to $72 \mathrm{~h}$. The insulin was injected subcutaneously in divided doses twice daily with the final dose administered $1 \mathrm{~h}$ prior to death.

The in vitro effect of insulin on aortic glucose metabolism was also examined in both control and diabetic aortas. In studies comparing diabetic with control aorta, the insulin $(25-100 \mu \mathrm{U} / \mathrm{ml})$ was added to incubation media containing the diabetic arteries, and its effect on glucose metabolism of total aorta was studied for a $2 \mathrm{~h}$ period. In studies of the effects of insulin on control aortas, the tissue was divided longitudinally into halves; one-half of the tissue was incubated in the presence of insulin $(100 \mu \mathrm{U} / \mathrm{ml})$ with the other half serving as its control.

The uptake of 2-deoxyglucose- ${ }^{\mathrm{I}} \mathrm{C}(5.0 \mathrm{mM})$ was examined in aortic segments over a 1 to $5 \mathrm{~min}$ period. Following incubation, the tissues were rinsed immediately $5 \mathrm{x}$ with $10 \mathrm{ml}$ ice cold saline, and the total tissue glucose, lipid, and glycogen radioactivity and medium lactate radioactivity were assayed as described above.

Blood glucose concentrations were analyzed on $0.05 \mathrm{ml}$ blood by the Auto-Analyzer microglucose procedure, and plasma insulin was determined on $0.1 \mathrm{ml}$ of plasma by a double antibody method using guinea pig anti-insulin serum [7]. Úrinary glncose was estimated by Testape ${ }^{\circledR}$ and urinary ketones by Ketostix ${ }^{\circledR}$. The ketotic diabetic animals were selected on the basis of consistently positive urinary ketones, whereas the non-ketotic diabetics were repeatedly negative by urinary Ketostix ${ }^{\circledR}$.

The purity of the labelled glucose utilized as determined by TLC, ranged from 98.4 to $99.3 \%$.

\section{Results}

\section{Plasma Glucose and Insulin}

Fasting blood glucose was significantly higher in both ketotic and non-ketotic animals than in the control group (Table 1). Significant reduction in fasting plasma insulin was observed in the ketotic hamsters but not in the non-ketotic diabetics when compared to their matched controls.

Insulin pre-treatment for $72 \mathrm{~h}$ prior to sacrifice was associated with significant decreases in blood glucose and increases in plasma immunoreactive insulin concentrations (Table 2). The changes were particularly marked at the dose of $30 \mathrm{U} / \mathrm{kg} /$ day when fasting blood glucose was reduced to below the normal range and plasma immunoreactive insulin was increased approximately 100 fold.

Table 1. Blood glucose and plasma insulin concentrations in control and diabetic Chinese hamsters

\begin{tabular}{lrl}
\hline Group & \multicolumn{1}{c}{ FBS } & FPI \\
\hline Control (for non-ketotics) & $95 \pm 10$ & $64 \pm 9$ \\
Diabetic (non-ketotic) & $288 \pm 24$ & $57 \pm 9$ \\
Control (for ketotics) & $102 \pm 13$ & $67 \pm 10$ \\
Diabetic (ketotic) & $352 \pm 29$ & $50 \pm 6$ \\
\hline
\end{tabular}

FBS = Fasting blood sugar

FPI $=$ Fasting plasma insulin

Results are expressed as the moan 1 SFM for 18 non-ketotic diabetics and their matched controls and 27 ketotics and controls.

Table 2. Influence of insulin therapy on blood glucose and plasma insulin in the diabetic hamster

\begin{tabular}{lllc}
\hline Group & Treatment & FBS & FPI \\
\hline Control & Saline & $104 \pm 9$ & $64 \pm 10$ \\
Diabetic & Saline & $335 \pm 34$ & $54 \pm 8$ \\
Diabetic & Insulin & & \\
& $(0.6 \mathrm{U} / \mathrm{kg} / \mathrm{d} \times 3 \mathrm{~d})$ & $125 \pm 14$ & $130 \pm 16$ \\
Diabetic & Insulin & & \\
& $(30.0 \mathrm{U} / \mathrm{kg} / \mathrm{d} \times 3 \mathrm{~d})$ & $78 \pm 10$ & $6520 \pm 680$ \\
\hline
\end{tabular}

The results are expressed as the mean \pm SEM for 27 saline treated diabetics, $\mathbf{1 2}$ low-dose insulin treated diabetics, 15 high-dose insulin treated diabetics, and 54 controls.

Aortic glucose utilization was significantly depressed in both ketotic and non-ketotic diabetic animals. The decreases were greatest in the ketotic animals where the reduction in total glucose metabolized averaged $42 \%$ below control values. In the aortas from non-ketotic diabetics, total glucose utilization averaged $22 \%$ less than the controls. All aspects of glucose utilization by diabetic aorta appeared to be similarly affected, with comparable decreases in incorporation of glucose to lactic acid, $\mathrm{CO}_{2}$, lipid, glycogen, and protein being observed (Fig. 1). Total aortic glucose uptake as determined by the disappearance of glucose from the medium increased in a linear manner with increasing medium glucose concentration over a range of $1-10 \mathrm{mM}$. 
Lactic acid was the major metabolite of glucose, with more than $80 \%$ of the glucose utilized being re. covered in this fraction (Table 3). Incorporation of glucose to $\mathrm{CO}_{2}$, lipid, glycogen, and protein accounted for less than $10 \%$ of total glucose metabolized. No significant differences were present between control and diabetic aorta in the percent incorporation of glucose into these metabolites.

Table 3. Metabolism of glucose by control and diabetic hamster aorta

\begin{tabular}{lcc}
\hline & $\begin{array}{c}\text { Control } \\
\text { (nmole glucose/mg }\end{array}$ & $\begin{array}{c}\text { Diabetic } \\
\text { DNA/2 h) }\end{array}$ \\
\hline Lactate & $22200 \pm 3410$ & $12400 \pm 2040$ \\
Pyruvate & $766 \pm 245$ & $378 \pm 122$ \\
CO $_{2}$ & $1170 \pm 162$ & $591 \pm 193$ \\
Lipid & $93 \pm 12$ & $44 \pm 13$ \\
Glycogen & $46 \pm 6$ & $19 \pm 5$ \\
Protein & $43 \pm 11$ & $21 \pm 9$ \\
\hline
\end{tabular}

Values represent the mean $\pm S E M$ for 7 separate studies. The diabetic animals utilized were ketotic.

Three aortas were included in each incubation.

Medrum glucose concentration was $5.0 \mathrm{mM}$.

Incubations were carried out for $2 \mathrm{~h}$.

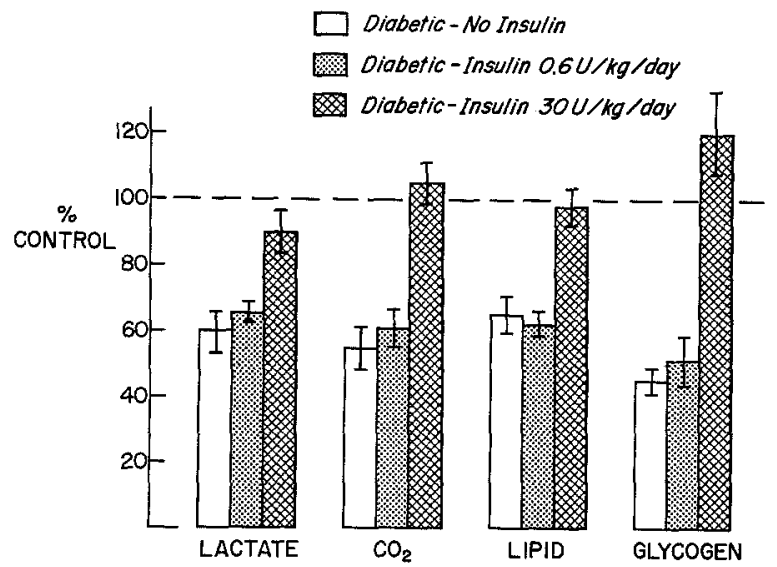

Fig. 1. The effects of insulin therapy on the metabolism of glucose by ketotic hamster aorta in vitro. The insulin was administered subcutaneously in divided doses at $12 \mathrm{~h}$ intervals over a period of 3 days. The results represent the per cent of control activity and are presented as the mean \pm SEM for 5 studies. Three aortas were utilized in each incubation

Insulin pre-treatment of the ketotic animals at a dose of $0.6 \mathrm{U} / \mathrm{kg} / \mathrm{day}$ for 3 days did not appear to correct the abnormalities in aortic glucose metabolism (Fig. 1) despite reductions in blood glucose and increase in fasting plasma immunoreactive insulin to greater than normal levels (Table 2). At the $30 \mathrm{U} / \mathrm{kg} /$ day dose of insulin administered for 3 days, aortic glucose utilization in the diabetic animals increased significantly, and the previously noted differences in incorporation of glucose to lactate, $\mathrm{CO}_{2}$, lipid, glycogen, and protein between the control and insulin-treated diabetics were eliminated (Fig. 1). However, when the high dose of insulin was given over a $24 \mathrm{~h}$ period, no influence on arterial glucose utilization occurred.

Insulin added in vitro did not produce significant changes in total glucose utilization in either the diabetic or control aortas (Table 4). Furthermore, no significant influence of insulin, added in vitro, on the aortic incorporation of glucose to lactate, $\mathrm{CO}_{2}$, lipid, or glycogen was present.

Table 4. Influence of insulin added in vitro on glucose- ${ }^{14} C$ incorporation by diabetic hamster aorta

\begin{tabular}{lll}
\hline \multirow{2}{*}{ Insulin } & \multicolumn{2}{l}{ Total aortic glucose utilization } \\
\cline { 2 - 3 } & $\begin{array}{l}\text { Control } \\
\text { (\% Control) }\end{array}$ & Diabetic \\
\hline 0 & 100 & $48 \pm 12$ \\
$25 \mu \mathrm{U} / \mathrm{ml}$ & $102 \pm 6$ & $45 \pm 18$ \\
$100 \mu \mathrm{U} / \mathrm{ml}$ & $108 \pm 12$ & $70 \pm 21$ \\
\hline
\end{tabular}

Values represent the mean \pm SEM for 7 studies.

Table 5. Relative incorporation of glucose-14C in vitro in control and diabetic hamster aorta

\begin{tabular}{llc}
\hline & Control & $\begin{array}{c}\text { Diabetic } \\
\text { (\% Lipid }\end{array}$ \\
\hline Phospholipid & $54 \pm 6$ & $57 \pm 5$ \\
Triglyceride & $35 \pm 4$ & $31 \pm 3$ \\
Free Fatty Acid & $1 \pm 0.5$ & $2 \pm 1$ \\
Sterol & $1 \pm 0.4$ & $2 \pm 1$ \\
Sterol Ester & $1 \pm 0.7$ & $\mathbf{1} \pm 1$ \\
\hline
\end{tabular}

Values represent the mean \pm SKM for 7 studies.

Table 6. Incorporation of glucose- ${ }^{14} \mathrm{C}$ to glycerol and fatty acid in normal and diabetic hamster aorta

\begin{tabular}{llr}
\hline & Control & Diabetic \\
& (\% Lipid Incorporation) \\
\hline Glycerol & $93 \pm 4$ & $94 \pm 6$ \\
Fatty Acid & $7 \pm 2$ & $6 \pm 2$ \\
\hline
\end{tabular}

Values represent the mean \pm SEM for 4 studies.

Table 7. Incorporation of 2-Deoxyglucose-14 $C$ into hamster aorta

\begin{tabular}{ll}
\hline & $\begin{array}{l}\text { Incorporation } \\
\text { (dpm/mg) }\end{array}$ \\
\hline Control & $6430 \pm \mathbf{1 8 4 0}$ \\
Diabetic & $5720 \pm 1420$ \\
\hline
\end{tabular}

Values represent the mean \pm SEM for 3 separate experiments. Incubation time $=5 \mathrm{~min}$.

The major incorporation of glucose into lipid occurred in the phospholipid moiety (Table 5). The relative incorporation into each lipid class was comparable in both diabetic and control aortas. Only negligible conversion into sterol and sterol esters was apparent. Following saponification, greater than $90 \%$ of lipid radioactivity was recovered in the glycerol moiety (Table $6)$. 
The total incorporation of 2-deoxyglucose did not differ significantly in control or diabetic hamster aorta over a $1-5 \mathrm{~min}$ incubation period (Table 7). No appreciable metabolism of 2-deoxyglucose to lactate, $\mathrm{CO}_{2}$, lipid, or glycogen was apparent.

\section{Discussion}

The aortas from diabetic hamsters had a consistent reduction in glucose utilization which was greater in the severely diabetic, ketotic animals than the milder, non-ketotic diabetics. The abnormalities in the diabetic hamsters did not appear to be secondary to a decrease in glucose transport into cells since no significant difference in uptake of the non-metabolized sugar, 2deoxyglucose, was present between the control and diabetic aortas. The results are consistent with the findings of Yalcin and Winegrad who demonstrated, by the measurement of glucose and raffinose spaces, that the transport of glucose into rabbit aorta was not rate limiting for subsequent utilization [20]. Insulin deficiency or relative insulin insensitivity could be important in the reduced aortic glucose utilization. Previous studies have suggested that glucose phosphorylation and hexokinase activity is diminished in aortas of the alloxan diabetic rabbits [21], and such a defect in phosphorylation could result in reduced glucose utilization. The markedly elevated free fatty acid and ketone levels in the diabetic hamster could also play a role by indirectly inhibiting glycolysis and glucose uptake, although such an explanation is not supported by the studies of Winegrad et al. in diabetic rabbits [21].

Several aspects of glucose metabolism appeared to be similarly affected in the diabetic arteries. The relative decreases in incorporation of glucose to lactate, pyruvate, $\mathrm{CO}_{2}$, lipid glycogen, and protein were comparable in the diabetic arteries. The results are generally similar to those observed in the alloxan-treated rabbit [1]. Lactate was the major product of arterial glucose metabolism in both control and diabetic arteries and represented greater than $80 \%$ of the total glucose utilized. These findings are comparable to those reported for arteries, of a number of different species including man $[22-26]$ and probably reflect the relatively high rate of glycolysis and low rate of mitochondrial oxidation in arterial tissue [27].

The abnormalities in glucose utilization in the arteries could be normalized by prior insulin treatment of the diabetic animals if massive doses of insulin were used. It is unclear why such large amounts of insulin were required since smaller amounts which were ineffective in influencing arterial metabolism were still sufficient to reduce blood sugar levels markedly and to increase plasma immunoreactive insulin concentrations to abnormally high levels. While the immunoreactive insulin concentration may not accurately reflect biological activity of the administered insulin, the reduction in blood glucose indicated the presence of biological activity. No significant effect on arterial wall metabolism occurred with a single dose of insulin, but $72 \mathrm{~h}$ of insulin therapy ultimately proved to correct the arterial abnormalities.

Insulin added in vitro had no significant effect on total aortic glucose utilization in either normal or diabetic hamster aorta. In addition, insulin did not appear to influence the incorporation of glucose into any of its metabolites when studied in vitro. The results are in agreement with our previous findings in human and canine arteries [22] and with the observations in rabbit aorta by Mulcahy and Winegrad [1]. Other in vitro effects of insulin on arterial tissue have been reported as inhibition of catecholamine stimulated lipolysis [28] and stimulation of phospholipid synthesis in arterial plaque tissue with high cellularity [29]. Insulin has also been shown recently to stimulate the proliferation of arterial smooth muscle cells in tissue culture [30].

The synthesis of all major lipid classes from glucose appeared to be depressed in the diabetic hamster aorta although the production rate could be increased to control levels with the administration of large doses of insulin. The role of insulin in the regulation of arterial lipid metabolism remains uncertain. Previous studies of Stout had suggested that insulin stimulated arterial lipogenesis in rats [4], although subsequent studies demonstrated that the action was limited to the arterial adventitia [5]. Increased arterial lipid content has been observed in chickens treated on a chronic basis with insulin [3]. The interpretation of these results is complicated by the fact that the animals also developed hyperlipidemia with insulin treatment and the hyperlipidemia itself may have contributed to arterial lipid deposition.

The relationship between the observed abnormalities in aortic glucose metabolism and the development of vascular lesions in the diabetic hamster is uncertain. Our preliminary studies to date would suggest that the level of serum lipids is a major factor contributing to arterial lipid deposition in these animals [12]. The recent studies of Morrison and associates suggest that hyperglycemia itself may have a detrimental effect on arterial tissue [31]. Accumulation of polyol derivatives and inhibition of arterial oxygen uptake were observed when arterial tissue was exposed in vitro to high medium glucose concentrations.

Acknowledgement. The authors gratefully acknowledge the skillful technical assistance of Ms. Margaret C. Blanks.

\section{References}

1. Mulcahy, P.D., Winegrad, A.I. : Efferts of insulin and alloxan diabetes on glucose metabolism in rabbit aortic tissue. Amer. J. Physiol. 203, 1038-1042 (1962)

2. Foster, D.W., Sipirstein, M.D.: Effects of diabetes on cholesterol and fatty acid synthesis in the rat aorta. Amer. J. Physiol. 198, 25-28 (1960) 
3. Stout, R.W.: The role of insulin in the development of atherosclerosis. In: Advances in Metabolic Disorders. Suppl. 2. Vascular and Neurological Changes in Early Diabetes. (Camerini-Davelos, R.A., Cole, H.S., eds.) pp. 41-47. New York: Academic Press 1973

4. Stout, R.W.: Insulin-stimulated lipogenesis in arterial tissue in relation to diabetes and atheroma. Lancet $1968 \mathrm{II}, 702-703$

5. Vost, A., Hollenberg, C.H.: Insulin and atherosclerosis. Lancet 1969 II, 218-219

6. Yerganian, G.: Spontaneous diabetes mellitus in the Chinese hamster, cricetulus griseus. IV. Genetic aspects. In: Aetiology of diabetes and its complications. Ciba Foundation Colloquia on Endocrinology. Vol. 15, pp. 25-41. Boston: Little, Brown \& Co. 1964

7. Gerritsen, G.C., Dulin, W.E.: Characterization of diabetes in the Chinese hamster. Diabetologia $\mathbf{3}, 74-$ 84 (1967)

8. Butler, L.: The inheritance of diabetes in the Chinese hamster. Diabetologia 3, 124-129 (1967)

9. Federman, J.L., Gerritsen, G.C.: The retinal vasculature of the Chinese hamster: A preliminary study. Diabetologia 6, 186-191 (1970)

10. Luse, S.A., Caramia, F., Gerritsen, G.C., Dulin, W.E.: Spontanoous diabetes mellitus in the Chinese hamster: An electron microscopic study of the islets of Langerhans. Diabetologia 3, 97-99 (1967)

11. Chobanian, A.V., Gerritsen, G.C.: Cholesterol metabolism in the diabetic hamster. J. elin. Invest. 50, 19a (1971)

12. Chobanian, A.V., Gerritsen, G.C., MeCombs, L., Brecher, P.I.: Arterial lipid metabolism in diabetic animal models with reduced or elevated plasma insulin levels. In: Proceedings of the third international symposium on atherosclerosis. Berlin, Heidelberg, New York: Springer 1974 (in press)

13. Washko, M.E., Rice, W. E.: Determination of glucose by an improved enzymatic procedure. Clin. Chem. 7 , $542-545(1961)$

14. Hohorst, J.J.: L- $(+)$-Lactate determination with lactic dehydrogenase and DPN. In: Methods of Enzymatic Analysis. (Bergmeyer, H.U., ed.) p. 266. New York: Academic Press 1965

15. Chobanian, A.V., Hollander, W.: Phospholipid synthesis in human blood vessels. J. clin. Invest. 45, $932-938$ (1966)

16. Folch, J., Lees, M., Sloane-Stanley, G.H.: A simple method for the isolation and purification of total lipides from animal tissues. J. biol. Chem. 226, 497$509(1957)$

17. Chobanian, A.V.: Effects of sex hormones on phospholipid, RNA, and protein synthesis in the arterial intima. J. Atheroscler. Res. 8, 763-775 (1968)

18. Ceriotti, G.: A microchemical determination of desoxyribonucleic acid. J. biol. Chem. 198, 297-303 (1952)
19. Spiro, R.G.: Studies on the biosynthesis of glucosamine in the intact rat. J. biol. Chem. 234, 742-748 (1959)

20. Yalcin, S., Winegrad, A.I.: Defect in glucose metabolism in aortic tissue from alloxan diabetic rabbits. Amer. J. Physiol. 205, 1253-1259 (1963)

21. Winegrad, A.I., Yalcin, S., Mulcahy, P.D.: Alterations in aortic metabolism in diabetes. In: On the nature and treatment of diabetes. (Leibel, B.S., Wrenshall, G.A., eds.) pp. 452-462. Amsterdam: Excerpta Medica Foundation 1965

22. Lille, R.D., Chobanian, A.V.: Pathways of arterial carbohydrate metabolism in human and animal intima. J. clin. Invest. 48, 53 a (1969)

23. Sbarra, A.J., Gilfallon, R.F., Bardawil, W.A.: The hexose monophosphate pathway in arterial tissue. Biochem. biophys. Res. Comm. 3, 311-313 (1960)

24. Beaconsfield, P.: Local metabolic response to physiopatholosical demands: The pentose phosphate pathway. Experientia 19, 437-438 (1963)

25. Mandel, P., Kemf, F.: The pentose phosphate pathway in the degradation of glucose by aortic tissue. $J$. Atheroscler. Res. 3, 233-236 (1963)

26. Lofland, H.B., Clarkson, T.B.: Certain metabolic patterns of atheromatous pigeon aorta. Arch. Path. 80, $291-296(1965)$

27. Kirk, J.E., Effersoe, P.G., Chiang, S.P.: The rate of respiration and glycolysis by human and dog aortic tissue. J. Gerontol. 9, 10-35 (1954)

28. Mahler, R.: Effect of insulin on lipid metabolism of human arteries. In: Advances in Metabolic Disorders, Suppl. 2, Vascular and Neurological Changes in Early Diabetes. (Camerini-Davelos, R.A., Cole, H.S., eds.) pp. 49-53. New York: Academic Press 1973

29. Björkerud, S.: Glucose lipogenesis in rabbit aorta in relation to age, degree of atherosclerosis, and the presence of insulin. In: Advances in Metabolic Disorders, Suppl. 2, Vascular and Neurological Changes in Early Diabetes. (Camerini-Davelos, R.A., Cole, H.S., eds.) pp. 55-63. New York: Academic Press 1973

30. Stout, R.W., Bierman, E.L., Ross, R.: The arterial smooth muscle cell: Insulin stimulation of cell proliferation. In: Proceedings of the third international symposium on atherosclerosis. Berlin, Heidelberg, New York: Springer.Verlag 1974 (in press)

31. Morrison, A.D., Clements, R.S., Jr., Winegrad, A.I.: Effects of elevated glucose concentrations on the metabolism of the aortic wall. J. clin. Invest. 51, $3114-3123(1972)$

Dr. Aram V. Chobanian Cardiovascular Institute

Boston University Medical Center Boston, MA 02118

USA 